\title{
Does Incorporating Healthy Lifestyle Education into Welfare-to-Work Programs Make a Difference?
}

\author{
Hala Madanat ${ }^{1,2 *}$, Marisa Molina1, Guadalupe X. Ayala ${ }^{1,2}$ \\ ${ }^{1}$ School of Public Health, San Diego State University, San Diego, CA, USA \\ ${ }^{2}$ Institute for Behavioral and Community Health, San Diego State University Research Foundation, San Diego, CA, USA \\ Email: ^hmadanat@sdsu.edu
}

How to cite this paper: Madanat, $\mathrm{H}$. Molina, M. and Ayala, G.X. (2018) Does Incorporating Healthy Lifestyle Education into Welfare-to-Work Programs Make a Difference? Health, 10, 1714-1718.

https://doi.org/10.4236/health.2018.1012129

Received: November 20, 2018

Accepted: December 11, 2018

Published: December 14, 2018

Copyright $\odot 2018$ by authors and Scientific Research Publishing Inc. This work is licensed under the Creative Commons Attribution International License (CC BY 4.0).

http://creativecommons.org/licenses/by/4.0/

\begin{abstract}
Objectives: This pilot study evaluated a healthy lifestyle program within the Welfare-to-Work program to help high-risk participants transition from welfare to employment. Methods: Nineteen Latinas enrolled in the California Work Opportunity and Responsibility to Kids (CalWORKs) program for more than six months participated in a 12-week intervention including six hours of employment-related training (ERT), two hours of healthy lifestyle classes, and two 1-hour exercise classes each week for 12 weeks. The women completed a survey and an anthropometric evaluation at baseline, 4- and 10-month post-baseline. CalWORKs participation and employment data also were collected. Additionally, aggregate data were collected for a comparison group meeting the same eligibility criteria and not participating in the 12-week intervention. Results: From baseline to 4-month, blood pressure, waist circumference, and body mass indices all decreased. Participants showed higher participation in ERT-related activities than the comparison group during and after the 12-week intervention. Employment rates were greater among the intervention versus comparison group participants and they were more likely to obtain employment of 20+ hours per week. Conclusions: This type of program benefits individuals in the Welfare-to-Work program on employment-related outcomes.
\end{abstract}

\section{Keywords}

Employment, Healthy-Lifestyle, Physical Activity, Intervention

\section{Introduction}

Between July 2013 and July 2014 more than 174,000 people were enrolled every 
month in California's version of the Temporary Assistance for Needy Families (TANF) program. This program is called California Work Opportunity and Responsibility to Kids (CalWORKs) and provides cash aid and services to eligible needy families [1]. Aid can only be received for 48 months in their lifetime making it extremely important to help recipients develop the skills necessary to obtain and maintain employment [2]. While receiving cash aid from the CalWORKs program, participants must be working, in school or participating in 32 - 35 hours of work activities each week. In order to fulfill these requirements, enrollees participate in the Welfare to Work (WTW) program, the employment and training part of CalWORKs.

Retention in the WTW program is a key component to recipients obtaining employment and being able to stop needing aid. Barriers to achieving these outcomes are the poor physical and mental well-being of recipients, who are more likely to suffer from depression, substance abuse, or have experienced domestic violence [3]. In 2010, the County of San Diego Health and Human Services Agency adopted the Live Well, San Diego! (LWSD) strategy, a 10-year plan aimed at building a healthy, safe and thriving community [4]. One strategy for ensuring the health and safety of San Diego County citizens is to promote three health behaviors: healthy eating, physical activity and tobacco cessation. Toward that end, Public Consulting Group (PCG), contracted to manage the WTW programs in South San Diego County, approached the Health and Human Services Agency (HHSA) South Region to integrate health and wellness education. HHSA approached the San Diego Prevention Research Center (SDPRC) to implement an evidence-based intervention developed by the SDPRC to satisfy the health and wellness component of this pilot study. A 12-week program was developed that combined the SDPRC's healthy lifestyle curriculum with a WTW employment-related curriculum designed by PCG. The purpose of this study was to evaluate the implementation of the healthy lifestyle program within the context of the WTW program with the goal of improving health outcomes and transitioning participants from welfare to employment.

\section{Methods}

This non-experimental pilot study was a partnership between PCG, HHSA, and the SDPRC.

CalWORKs recipients were eligible to participate in the pilot study if they were between 18 - 69 years of age, unemployed for longer than six months, not enrolled in school or working full-time, Spanish-speaking or bilingual Spanish/English, able to participate in physical activity, and required to participate in the WTW program.

The 12-week program combined employment-related training of the WTW program and the SDPRC's Community Health Worker-led Familias Sanasy Activas (Healthy and Active Families) healthy lifestyle and exercise program. The employment-related training provided by PCG included topics such as work 
motivation, barrier awareness, job market navigation, presentation skills, dealing with fears, resume building, filling out applications, avoiding job burnout, networking, interview strategies, managing personal finances, time management, and job retention. The healthy lifestyle curriculum taught participants how to set SMART goals each week for different health behaviors including but not limited to: physical activity, healthy eating, sleep, communication and relationships. The curriculum also provided tools and role played conversations for improving personal and family emotional health, overcoming barriers to changing health behaviors, and how to resolve conflicts. Over the course of three days, every week for 12 weeks, the participants had six hours of employment-related, two hours of healthy lifestyle classes, and two 1-hour aerobics/Zumba-type exercise classes. Day one included 2.5 hours of employment-related training and one hour of exercise. Day two included 3.5 hours of employment-related training. Day three included a two-hour healthy lifestyle class and one hour of exercise. Healthy lifestyle classes were conducted by a Community Health Worker trained by the SDPRC.

Data were collected from July 2013 to February 2014. Participants were evaluated at baseline, 4- and 10-months post baseline. Evaluation procedures included a one-hour interview, measurement of height, weight, waist circumference, and blood pressure conducted by research assistants trained by the SDPRC using established protocols [5] [6]. CalWORKs participation and employment achieved were collected and tracked for all participants by PCG. Aggregate data for CalWORKs participation and employment were also collected from a comparison group of 335 persons enrolled in CalWORKs that met the same eligibility criteria but did not participate in the 12-week intervention. Data were summarized using non-parametric descriptive statistics assessing health status at each measurement point (baseline, 4- and 10-months post baseline). CalWORKs participation and employment status of the participants were compared to the aggregate data for the comparison group.

\section{Results}

Demographic characteristics of participants are presented in Table 1. All 19 participants were women; most were unmarried $(57.9 \%)$ and had at least a high school education (57.9\%). The average age of these women was 36.2 years. At 4-months post baseline, 16 of the participants were reached and at 10-months post baseline, 12 of the participants were reached. From baseline to 4-months post-baseline, systolic blood pressure (114.68 to $113.13 \mathrm{mmHg}$ ), diastolic blood pressure $(70.74$ to $68.38 \mathrm{mmHg}$ ), waist circumference $(99.0$ to $98.01 \mathrm{~cm}$ ) and BMI (30.13 to $29.36 \mathrm{~kg} / \mathrm{m}^{2}$ ) all decreased. Diastolic blood pressure (68.7 $\mathrm{mmhg}$ ), waist circumference $(98.12 \mathrm{~cm})$ and BMI $\left(29.47 \mathrm{~kg} / \mathrm{m}^{2}\right)$ increased from 4- to 10-months but remained lower than baseline levels (see Table 1). Intervention participants had higher average CalWORKs participation hours and showed increased engagement in CalWORKs activities even after the 12-week intervention 
Table 1. Demographic characteristics and health status of intervention participants at baseline, 4- and 10-months post baseline.

\begin{tabular}{cccc}
\hline & Baseline $(\mathrm{n}=19)$ & 4 -months $(\mathrm{n}=16)$ & 10 -months $(\mathrm{n}=12)$ \\
\hline Average age in years & 36.21 & - & - \\
Median household size & 4 & - & - \\
\% unmarried $(\mathrm{n})$ & $57.9(11)$ & - & - \\
\% high school education or more & $57.9(11)$ & - & 111.50 \\
Systolic blood pressure $(\mathrm{mmHg})$ & 114.68 & 113.13 & 68.67 \\
Diastolic blood pressure $(\mathrm{mmHg})$ & 70.74 & 68.38 & 29.47 \\
Body Mass Index $\left(\mathrm{kg} / \mathrm{m}^{2}\right)$ & 30.13 & 29.36 & 98.12 \\
Waist Circumference $(\mathrm{cm})$ & 99.00 & 98.01 & \\
\hline
\end{tabular}

(54\% vs. $30 \%$ ) compared to comparison group participants. Intervention group participants' employment rates were greater than the comparison group participants' at each month of assessment: October ( $26 \%$ vs. $6 \%$ ), November (37\% vs. $13 \%)$ and December (42\% vs. $10 \%$ ). They also were more likely to obtain employment of $20+$ hours per week over those three months: October ( $26 \%$ vs. $4 \%$ ), November (37\% vs. $8 \%$ ) and December (37\% vs. $7 \%)$.

\section{Discussion}

Many WTW work programs measure their success from two perspectives: 1) participant perspective (costs and benefits to the participant including change in income/public assistance payments) and 2) governmental budget perspective (public assistance payments and administrative costs) [7]. Study results suggest that a program that combines health, wellness and employment-related training can be effective for both the individual and the institution. Additionally, it should be noted that intervention group participants were considered a high-risk population, given that they were recipients of public assistance for more than six months. This suggests that this program may produce stronger results with the general CalWORKs population and should be further studied. The study was limited by the small sample size and focused exclusively on Spanish-speaking Latina women. Further research is warranted to test the effectiveness of this model with a larger, more diverse sample including men and other racial/ethnic groups. Additionally, there were 7 participants who were unreachable at the 10-month follow-up, further reducing the sample size. Mechanisms for increasing program retention are needed and should be tested for this unique population. This study sought to increase the number of participants who transitioned from aid to employment, with the intention of having fewer people receiving public assistance. Further studies should measure cost-effectiveness and examine the impact of the program after one year in a larger and more diverse sample.

\section{Conclusion}

More research should be done to determine the effectiveness of programs dedi- 
cated to improving the mental and physical health of welfare recipients as a way to support recipients to obtain and maintain employment. From the perspective of the state or federal government, this type of program could also reduce public assistance payments and administrative costs.

\section{Acknowledgements}

The study was funded by CDC (U48-DP001917) to Dr. John P. Elder, SDPRC Director and Principal Investigator; Dr. Guadalupe X. Ayala, Research Core Principal Investigator and SDPRC Co-Director; and Dr. Lisa Madlensky, SDPRC Co-Director. CDC/PRC had no role in the study design, data collection, data analyses, data interpretation, writing this report, or the decision to submit for publication.

\section{Conflicts of Interest}

The authors declare no conflicts of interest regarding the publication of this paper.

\section{References}

[1] California Department of Social Services (2015) California Work Opportunity and Responsibility to Kids (CalWORKs). http://www.cdss.ca.gov/calworks

[2] Hildebrandt, E. and Stevens, P. (2009) Impoverished Women with Children and No Welfare Benefits: The Urgency of Researching Failures of the Temporary Assistance for Needy Families Program. American Journal of Public Health, 99, 793-801. https://doi.org/10.2105/AJPH.2006.106211

[3] U.S. Department of Health and Human Services Administration for Children and Families (2000) Welfare Reform: Employment Strategies for Overcoming Substance Abuse/Mental Health Barriers.

https://peerta.acf.hhs.gov/sites/default/files/public/uploaded_files/Final\%20Report_ Substance\%20Abuse.pdf

[4] County of San Diego Health and Human Services Agency (2011) About Live Well San Diego. http://www.livewellsd.org/content/livewell/home/about.html

[5] Centers for Disease Control and Prevention (2005a) NHANES Cardiovascular Fitness Procedures Manual. http://www.cdc.gov/nchs/data/nhanes/nhanes_05_06/CV.pdf

[6] Centers for Disease Control and Prevention (2005b) NHANES Anthropometry Procedures Manual. http://www.cdc.gov/nchs/data/nhanes/nhanes_09_10/BodyMeasures_09.pdf

[7] Greenberg, D., Deitch, V. and Hamilton, G. (2009) Welfare-to-Work Program Benefits and Costs: A Synthesis of Research. https://www.mdrc.org/publication/welfare-work-program-benefits-and-costs 